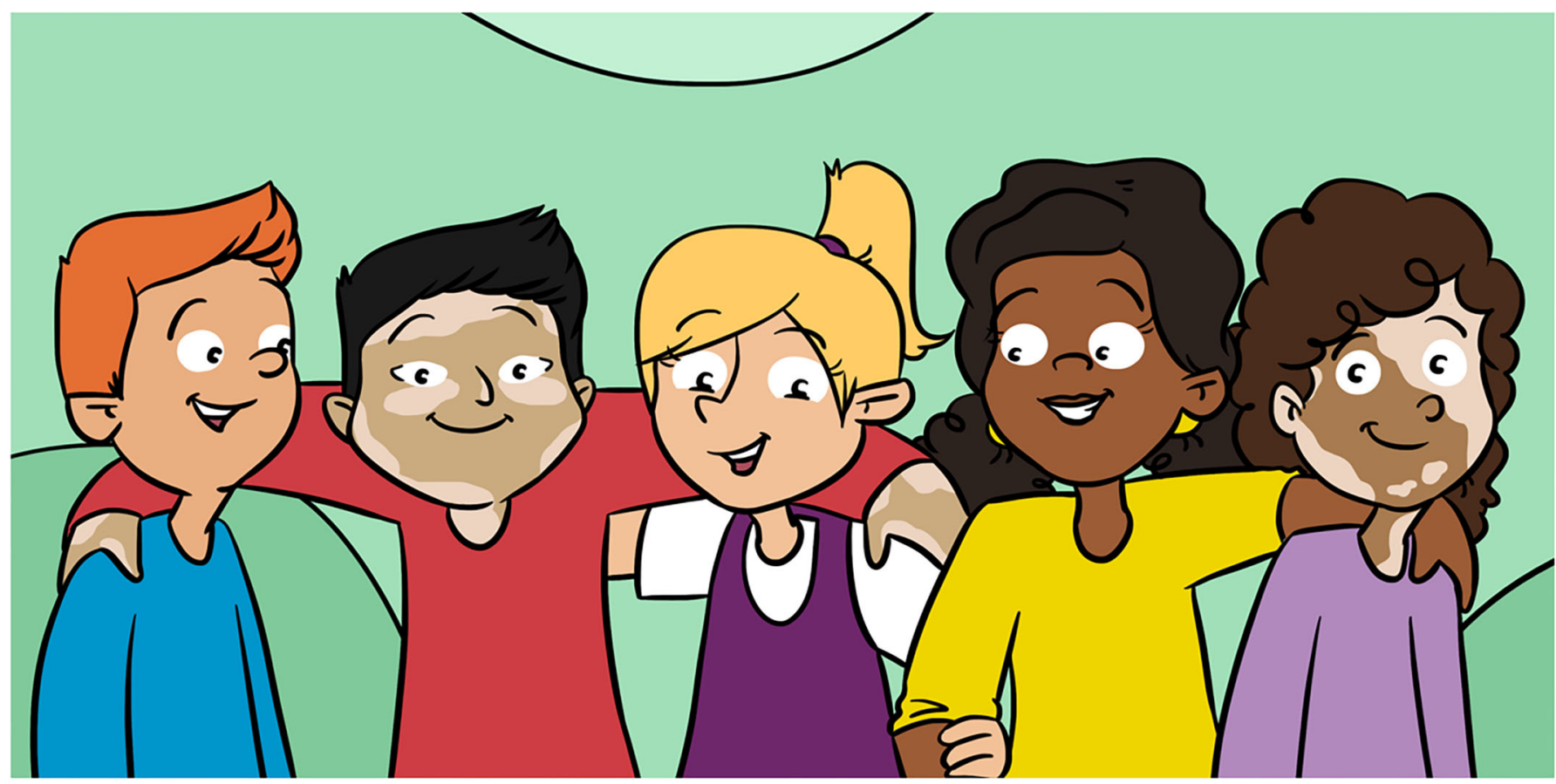

\title{
WHAT IS VITILIGO AND HOW CAN IT TEACH US A CRUCIAL LIFE LESSON?
}

\section{Nicholas Leonard * and Jillian M. Richmond *}

Department of Dermatology, University of Massachusetts Medical School, Worcester, MA, United States

\section{YOUNG REVIEWERS:}

CRESCENT

GIRLS'

SCHOOL

AGES: $15-16$

SOPHIA

AGE: 12

\section{MELANIN}

A pigment in our body that both gives skin its color and also protects it from ultraviolet light from the sun.
So, what is vitiligo? Vitiligo is a condition in which people lose the cells in the skin that give it color. These cells are called melanocytes. Vitiligo leaves affected individuals with white spots scattered across their skin. This article includes background information on skin structure. It then explores the causes and treatment of vitiligo. Finally, we discuss the impact vitiligo can have on mental health.

\section{WHAT GIVES SKIN ITS COLOR?}

Let us start with the basics! There is something in human skin called melanin. Melanin is a type of pigment and it gives skin color. Melanocytes are the cells that produce melanin.

Like an onion, the skin is made up of many layers. Melanin is stored in the top layer of skin, called the epidermis. At the very bottom of the epidermis, there is a layer called the basal layer, which is where the melanocytes live. But what do melanocytes do with all the melanin they produce? They do not just keep it all to themselves! 
MELANOCYTES

Cells that make melanin, the pigment in the skin.

\section{EPIDERMIS}

The top portion of our skin made up of layers of cells including keratinocytes and melanocytes among others.

\section{BASAL LAYER}

The bottom layer of the epidermis which is where melanocytes are normally found.

\section{KERATINOCYTES}

Cells that make up the top layer of skin, called the epidermis, and provide a barrier to the outside world. They store melanin in melanosomes, which helps protect them from UV damage and gives skin its color.

\section{MELANOSOMES}

Packages of melanin that are passed from melanocytes to keratinocytes.

\section{DEPIGMENTATION}

Loss of skin pigment or coloration.

\section{AUTOIMMUNE}

\section{DISEASE}

Condition in which the immune system attacks the body's own cells instead of things that can cause disease.
They share the melanin with neighboring cells, called keratinocytes, by sending them packages of melanin called melanosomes (Figure 1). Keratinocytes use the melanin in the melanosomes to shield their DNA from dangerous ultraviolet (UV) light from the sun, much like beach-goers might use umbrellas to shield themselves. Melanin production increases when we are exposed to UV light. This is the reason that people can become tan after being outside for a while. Keep in mind that melanin is far from a perfect protector. You know this if you have ever had a bad sunburn...ouch! We can help melanin do its job by wearing sunscreen, big hats, and sun-protective clothing when we are in the sun.

\section{WHAT IS VITILIGO AND WHAT CAUSES IT?}

Now that we know about melanin, let us talk about vitiligo. Vitiligo is the most common cause of people losing the color in their skin, which is also called depigmentation. One out of every 100 people have vitiligo. Individuals of all different genders, races, locations, and social status are affected [1]. People with vitiligo have small white spots or larger white patches on their skin. The melanocytes in these areas have been destroyed, and therefore, they have no more melanin. A small number of patients will experience inflammation (pink and scaly skin), but most patients do not have a noticeable amount of inflammation. Vitiligo most commonly affects the skin of the hands and face (Figure 2). Scientists are still trying to understand why certain areas of skin may be unaffected in individuals with vitiligo.

Doctors and scientists are working hard to understand how and why melanocytes are destroyed in vitiligo. After years of research, we have started to uncover important pieces to the puzzle. Have you heard of the immune system? It is a very important part of the body that fights infections. The immune system is made up of white blood cells, which normally protect us from things that can make us sick, such as bacteria, viruses, and even pre-cancerous cells. Vitiligo is an autoimmune disease [2]. In autoimmune diseases, the white blood cells get confused and start attacking the body's own cells instead of the disease-causing cells and viruses they are supposed to target. This is like a soccer player who forgets which net is which and accidentally scores on his own team! In the case of vitiligo, a type of white blood cells called $\mathrm{CD}^{+}{ }^{+} \mathrm{T}$ cells attack and kill the melanocytes (Figure 2) [2].

Like many other autoimmune diseases, we think that vitiligo is caused by a mixture of genetics and environment. In terms of genetics, we know that people who inherit certain genes from their parents are more likely to develop vitiligo. However, we know it is not only genes that determine if someone will develop vitiligo. For example, identical twins (with the same DNA) do not always both have vitiligo. This means that an environmental trigger is also important. In terms 


\section{Figure 1}

Normal skin structure and pigmentation. The top layer of the skin is called the epidermis and the bottom layer is the dermis.

Melanocytes live in the bottom layer of the epidermis, called the basal layer, which is right above the dermis. Immune cells pass by in the blood vessels in the underlying dermis. Melanin is sent from the branching melanocyte to the surrounding keratinocytes, in melanosomes, which are little bubbles of melanin. The melanosomes stay inside the keratinocytes as the keratinocytes move toward the top of the skin, where this stored melanin gives pigmentation to the skin surface.

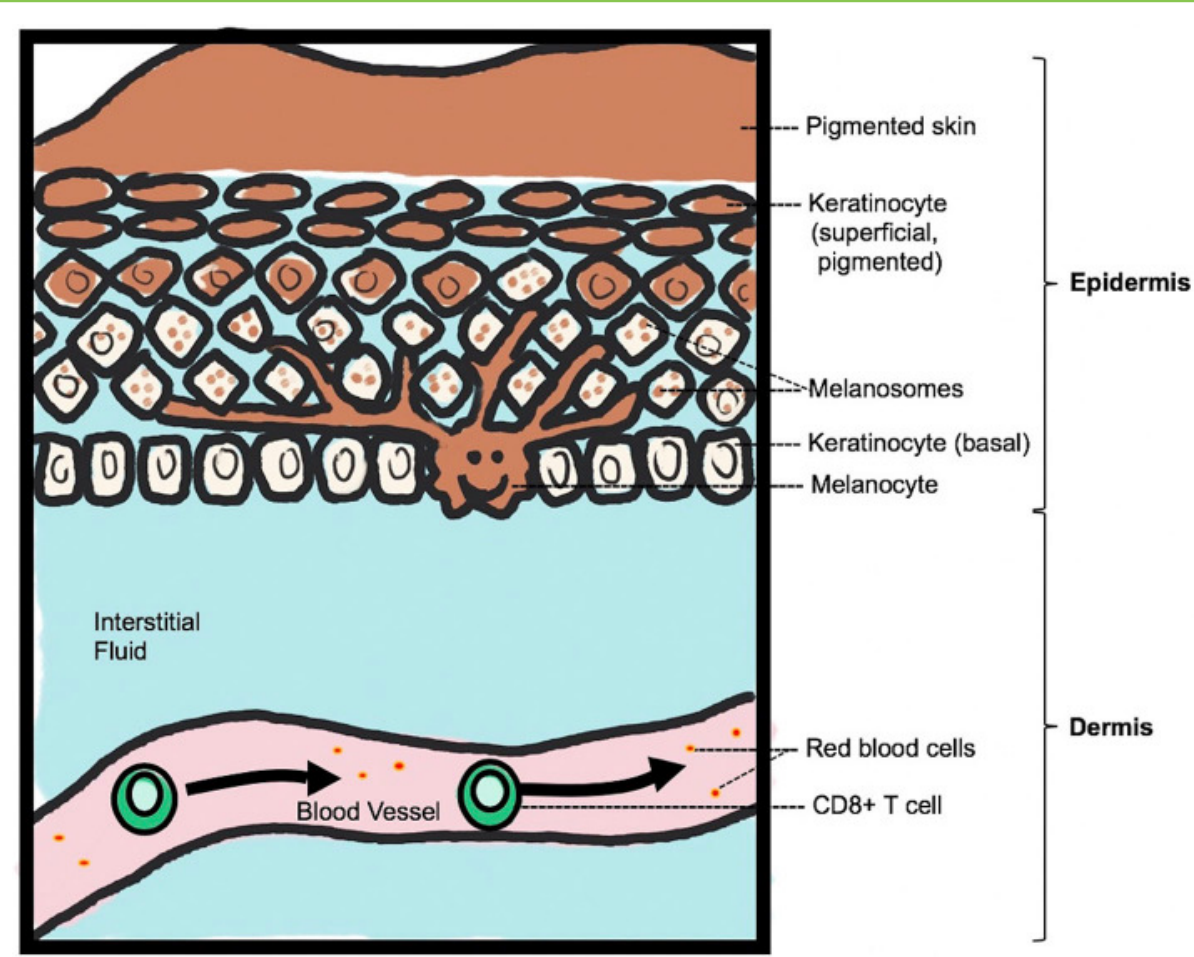

Figure 1

of specific environmental triggers, there are a few examples of chemical exposures that can lead to vitiligo. For example, hair dyes, skin-lightening creams, and adhesives have been linked to cases of vitiligo. We also think that these chemicals cause melanocyte stress because they can interfere with melanin production. The stressed-out melanocytes send out danger signals to the white blood cells, which may trigger the autoimmune response against melanocytes.

\section{HOW DO DOCTORS TREAT VITILIGO?}

Treatment of vitiligo has historically focused on medications that calm down the immune system. Corticosteroids are an example of medications used for this purpose. These treatments force the immune system to leave the melanocytes alone. Corticosteroids can be applied topically, meaning on top of small areas of affected skin, as a cream or lotion. They can also be taken by mouth in pill form, which allows the medicine to reach all parts of the body. Another interesting and effective treatment for vitiligo is phototherapy. Phototherapy involves the use of specific types of light, like narrow-band ultraviolet light type $B(U V B)$. This therapy is important because it helps stimulate the melanocytes to grow back. Combining medications that calm down the immune system and UVB therapy seems to be the most effective way to restore pigment in vitiligo patients. Some downsides to treating vitiligo include thin skin for patients who use topical steroids for a long time, as well as a weakened immune system that makes 
Figure 2

Depigmented skin in a person with vitiligo. Melanocytes in the bottom layer of the epidermis are attacked by white blood cells, called $\mathrm{CD}^{+}{ }^{+} \mathrm{T}$ cells, that leave blood vessels in response to a stress signal and enter the dermis. Because the melanocytes are no longer there to give them melanosomes, melanin is not present in keratinocytes and therefore the skin surface is depigmented.

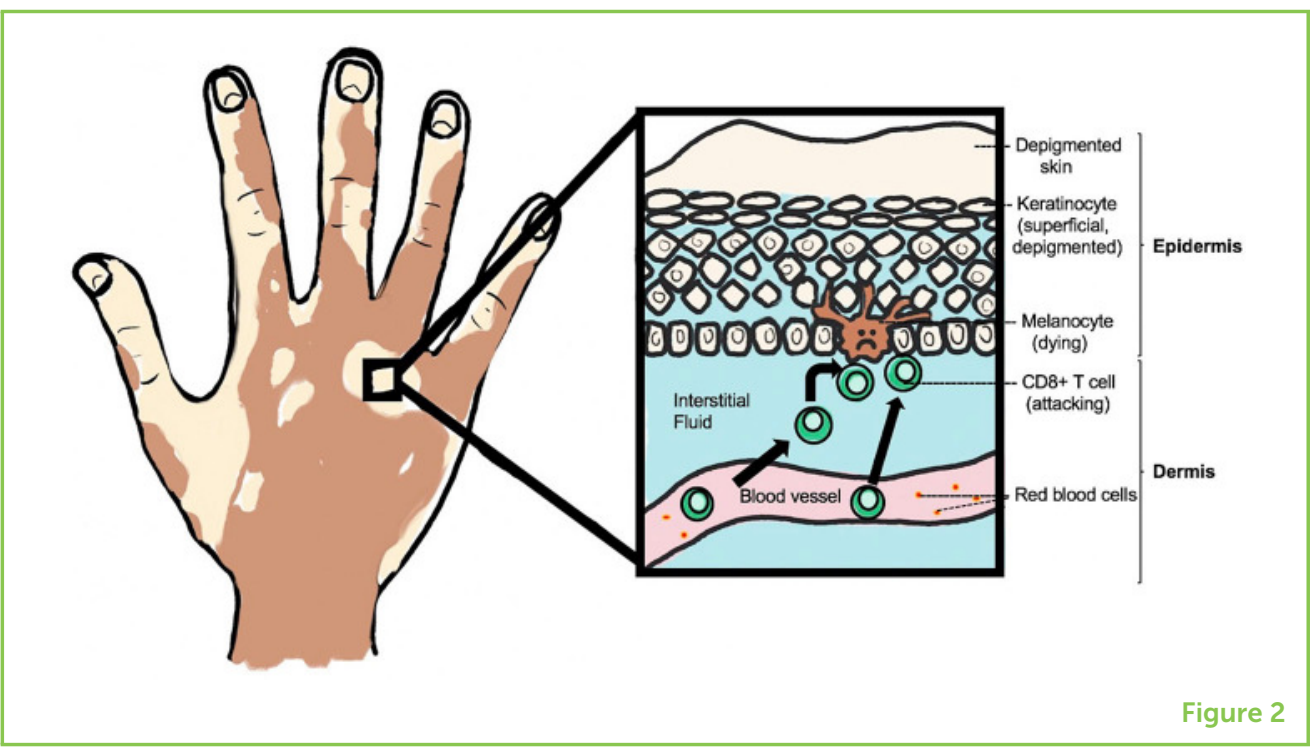

them more likely to catch skin viruses like those that cause warts. Many patients feel that the benefits of treating their vitiligo outweigh these risks.

Even though these treatments can help, we currently do not have a cure for vitiligo. If a patient stops treatment, the white spots often reappear in the same location. This tells us that the treatments used today can mask or slow the disease, but they do not permanently fix it. We think this occurs because of a special type of long-lived immune cell called a resident-memory $T$ cell (Trm). These Trms are resilient cells: they are equipped to hide out in the skin throughout treatment, and start an immune response if medicines are stopped. We recently tested a new type of treatment that might work to prevent these Trms from doing their job. This treatment would be injected directly into the skin or into the blood vessels and would provide a much more long-lasting treatment option [3]. A new round of testing will start soon, to test how well this type of therapy works for vitiligo.

\section{HOW DOES VITILIGO IMPACT A PERSON'S LIFE?}

It is important to know that many people choose not to treat their vitiligo at all, and that is okay! Besides the lack of pigment, the skin in vitiligo patients is completely normal and healthy. It is usually not painful or irritated. If you closed your eyes and ran your hand over the area, it would not feel any different than the surrounding skin. People with vitiligo also do not have an increased risk of skin cancer. Some scientists think that the active immune system in the skin of vitiligo patients may actually help protect them against skin cancers. Many individuals with vitiligo embrace their visual difference. They proudly display their uniqueness and choose not to treat it at all. People with vitiligo oftentimes praise this condition for teaching them 
important life lessons. Many learn the power of self-confidence as well as acceptance and appreciation for differences in others, both inside and out.

Can vitiligo still be harmful to affected individuals? The answer is yes. One of the hardest parts about living with vitiligo are the negative feelings that can come from looking different. Many people with vitiligo often have lower self-esteem and increased rates of anxiety and depression [4]. Make sure you keep this in mind when you spend time with people affected by vitiligo and other skin conditions. Vitiligo is not an infection. It is not contagious. And we should not fear or judge those who are affected. Therapies can limit the impact of vitiligo, but being kind and welcoming to individuals with this condition may be the most helpful thing we can do for them.

\section{REFERENCES}

1. Zhang, Y., Cai, Y., Shi, M., Jiang, S., Cui, S., Wu, Y., et al. 2016. The prevalence of vitiligo: a meta-analysis. PLOS ONE 11:e0163806. doi: 10.1371/journal. pone.0163806

2. Frisoli, M. L., Essien, K., and Harris, J. E. 2020. Vitiligo: mechanisms of pathogenesis and treatment. Annu. Rev. Immunol. 38:621-48. doi: 10.1146/ annurev-immunol-100919-023531

3. Richmond, J. M., Strassner, J. P., Zapata, L. Jr., Garg, M., Riding, R. L., Refat, M. A., et al. 2018. Antibody blockade of IL-15 signaling has the potential to durably reverse vitiligo. Sci. Transl. Med. 10:eaam7710. doi: 10.1126/scitranslmed. aam7710

4. Salzes, C., Abadie, S., Seneschal, J., Whitton, M., Meurant, J., Jouary, T., et al. 2016. The Vitiligo Impact Patient Scale (VIPs): development and validation of a vitiligo burden assessment tool. J. Invest. Dermatol. 136:52-8. doi: 10.1038/ jid.2015.398

SUBMITTED: 18 July 2020; ACCEPTED: 11 May 2021;

PUBLISHED ONLINE: 08 June 2021.

EDITED BY: Bergithe Eikeland Oftedal, University of Bergen, Norway

CITATION: Leonard N and Richmond JM (2021) What Is Vitiligo and How Can It Teach Us a Crucial Life Lesson? Front. Young Minds 9:584941. doi: 10.3389/frym. 2021.584941

CONFLICT OF INTEREST: JR is an inventor on patent application \#62489191, "Diagnosis and Treatment of Vitiligo" which covers targeting IL-15 and Trm for the treatment of vitiligo; and on patent application \#15/851,651, "Anti-human CXCR3 antibodies for the Treatment of Vitiligo" which covers targeting CXCR3 for the treatment of vitiligo. 

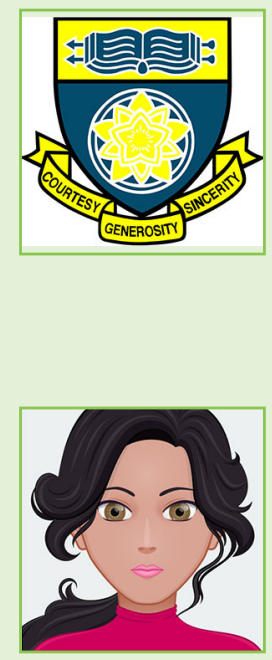

The remaining author declares that the research was conducted in the absence of any commercial or financial relationships that could be construed as a potential conflict of interest.

COPYRIGHT () 2021 Leonard and Richmond. This is an open-access article distributed under the terms of the Creative Commons Attribution License (CC BY). The use, distribution or reproduction in other forums is permitted, provided the original author(s) and the copyright owner(s) are credited and that the original publication in this journal is cited, in accordance with accepted academic practice. No use, distribution or reproduction is permitted which does not comply with these terms.

\section{YOUNG REVIEWERS}

\section{CRESCENT GIRLS' SCHOOL, AGES: 15-16}

We are a group of young inquisitive students with a keen interest in science. We love to gain new insights and perceive science with a critical eye. We develop a passion for the Sciences that goes beyond our curriculum and syllabus. We had a very enlightening experience as this reviewing process was something out of the ordinary for all of us! Together we are Julia, Harnoor, Srija, Dhaaniya, Mai, Xiangyu, Roopa, Sybil, and Sarranya.

\section{SOPHIA, AGE:12}

My name is Sophia, I am 12 years old. I am Brazilian and love to play with my friends and watch videos on the internet.

\section{AUTHORS}

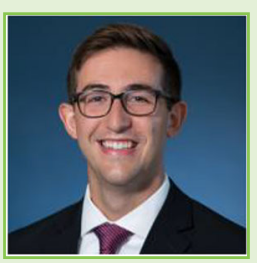

\section{NICHOLAS LEONARD}

Nicholas is a medical student in his last year of studies at the University of Massachusetts Medical School. He earned his B.S. in biology from Boston College. $\mathrm{He}$ is applying to become a dermatologist and hopes to work with individuals with vitiligo and all different types of skin conditions in the future. When he is not in the clinic or library, you can find him hiking, cooking, and spending time with friends and family. *nicholas.leonard@umassmed.edu

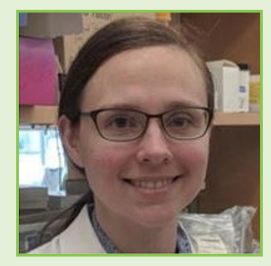

\section{JILLIAN M. RICHMOND}

Jillian is an Assistant Professor of Dermatology at the University of Massachusetts Medical School. She earned her B.S. in molecular and cellular biology from Johns Hopkins University and her Ph.D. in immunology and pathology from Boston University School of Medicine. Her laboratory studies the role of the immune system in skin diseases. She is the faculty advisor for the Dermatology Interest Group Journal Club at UMass. Jillian is passionate about teaching and mentoring students in the classroom and the laboratory and discovering new treatments for patients through her research. She enjoys spending time with her kids, baking, and gardening. *jillian.richmond@umassmed.edu 